\title{
Correction to: Estimating Measurement Uncertainty on Stress-Strain Curves from SHPB
}

\author{
D. Brizard ${ }^{1} \cdot$ S. Ronel ${ }^{1} \cdot$ E. Jacquelin ${ }^{1}$
}

Published online: 3 May 2021

(c) Society for Experimental Mechanics 2021

The correction article has been updated to include the missing square in the left side of equation (5).

This error was introduced during production process and was not the fault of authors.

Publisher's Note Springer Nature remains neutral with regard to jurisdictional claims in published maps and institutional affiliations.

The original article can be found online at https://doi.org/10.1007/ s11340-020-00617-1.

D. Brizard

denis.brizard@univ-eiffel.fr

S. Ronel

sylvie.ronel@univ-lyon1.fr

E. Jacquelin

eric.jacquelin@univ-lyon1.fr

1 Univ Lyon, University Claude Bernard Lyon 1, IFSTTAR,

LBMC UMR T9406, F69622 Lyon, France 